\title{
LOS BAILES DE JALEO, PRECEDENTES DIRECTOS DE LOS BAILES FLAMENCOS
}

\section{JALEO DANCES, DIRECT PRECEDENTS OF FLAMENCO DANCES}

\author{
Miguel Ángel Berlanga \\ Universidad de Granada
}

\begin{abstract}
Resumen
En este artículo se estudia la conexión histórica entre el baile flamenco y un tipo de danzas a sólo que cobraron especial auge entre el último tercio del siglo XVIII y la primera mitad del XIX, de las que se argumenta también conexiones con algunas antiguas danzas del teatro español. Aunque con caracteres distintivos cada una de ellas (zorongos, vitos, olés, cachuchas...), algunos rasgos comunes justifican su designación conjunta como jaleos, bailes de jaleo, danzas mixtas o danzas teatrales andaluzas.

Además de argumentar que las tiranas fueron la principal designación genérica de las canciones de los jaleos teatrales, se propone que los primeros bailes flamencos pueden considerarse $j a$ leos populares agitanados, y que su progresivo perfeccionamiento técnico les vino en buena parte de su continuado contacto con los jaleos teatrales.
\end{abstract}

\footnotetext{
Palabras clave tiranas.

Bailes de jaleo; baile flamenco; bailes teatrales andaluces;
}

\section{INTRODUCCIÓN}

La teorización sobre los orígenes del flamenco se ha basado hasta hace no mucho en el cante, del que se decía "surgido del hogar gitano" sin casi aludir a los materiales andaluces con que los gitanos lo habrían forjado (MOLINA/ MAIRENA,1979: 26-27). En esos discursos, no solo el baile fue casi ignorado, también la guitarra llegó a considerarse un añadido posterior al cante a palo seco de romances y tonás, que se retenían como los más auténticos y originarios por el mero hecho de que sonaban a más primitivos.

\begin{abstract}
This article discusses the historical connection between flamenco dancing and a kind of solo-dances, which took on special heyday between the last third of the eighteenth century and the first half of the nineteenth. In addition, we argue its connection with other dances in the oldest Spanish theater. Zorongos, vitos, olés, cachuchas... although each of them had distinctive features, they also had some common features that justify they can be called jaleos, jaleo-dances, or theatrical Andalusian dances.

We argue that tiranas were just jaleos songs. Furthermore we argue that the first flamenco dances can be considered "gypsized jaleos", and its progressive technical refinement was due, mainly, to its continuous contact with the theatrical jaleos.
\end{abstract}

\section{Keywords} tiranas.

Jaleo dances; flamenco dance; Andalusian Theatrical dances;

Este estado de cosas ha ido cambiando, de forma que hoy día somos conscientes de que sin el estudio del baile, los precedentes históricos del flamenco -que es cante, toque y baile- quedan obscuros, desdibujados. La publicación en 1990 de ¿Se sabe algo? de Ortiz Nuevo supuso un hito en este sentido, pues contribuyó a aceptar el dato del encuentro histórico que se produjo en las academias de baile -particularmente las de Sevilla desde 1840-50 en adelante-, entre el baile gitano, expresivo y rico en "esencias" aunque aún pobre técnicamente, y el más desarrollado de las bailarinas boleras que coincidieron con las bailaoras gitanas: en esos 
espacios habría tenido lugar la primera integración entre los pasos del baile académico español y el estilo y modos de los bailes gitanos. Amparo Álvarez, La Campanera, sería una de las primeras bailarinas boleras y flamencas, de las primeras en dominar ambos códigos.

Pero transcurrido un cuarto de siglo de la citada publicación, necesitamos profundizar en el diálogo que de hecho supuso el flamenco entre ámbitos populares y académicos o teatrales, y afinar el concepto de bailes andaluces y gitanos: ¿qué tipo de bailes gitanos eran lo que interactuaron con la "técnica bolera" en las academias de mediados del siglo XIX? ¿Qué precedentes encontramos de esos primitivos bailes flamencos? Y la danza de bailarinas como Amparo Álvarez, Petra Cámara o Manuela Perea ¿Era danza bolera -sin más especificaciones- o más bien un tipo específico de danzas?

En un trabajo anterior argumentamos sobre los bailes de candil como ámbitos festivos que el flamenco retomó: las primeras fiestas flamencas podían entenderse como una transformación del ritual de esas fiestas (BERLANGA, 2000). Aquí nos centraremos en el tipo de bailes cuyo agitanamiento o aflamencamiento habría dado lugar a los primeros bailes flamencos.

Nuestra principal hipótesis puede formularse así: no fueron los bailes de pareja o de palillos (tipo fandangos y sevillanas, los más abundantes en esas fiestas) los que más influyeron en el surgimiento de los primeros bailes flamencos, sino los jaleos, una categoría genérica de danzas a sólo que también aparecían en muchas fiestas populares andaluzas. Y que una vez "transformadas" en jaleos agitanados, su continuo contacto - especialmente desde la década de 1840 con sus versiones académicas o jaleos teatrales, contribuyó a su perfeccionamiento técnico. Si los bailes de candil pueden considerarse fiestas preflamencas, los jaleos fueron los precedentes más directos del baile flamenco.

Esta hipótesis no soslaya el protagonismo clave de muchos artistas gitanos, que desde los inicios del flamenco han contribuido a otorgarle su ethos particular. Simplemente considera el flamenco más que como "nueva creación" a partir de no se sabe bien qué, como una recreación -todo lo genial que se quiera- a partir de tradiciones previas.

Para argumentar todo esto, necesitamos integrar los datos de que disponemos sobre los bailes practicados en Andalucía en los años previos y coetáneos al primer flamenco. Englobaremos este diálogo entre bailes gitanos y académicos en uno más amplio entre danzas de ámbitos populares/festivos y danzas de ámbito académico/teatral, cuyo momento de auge cabe situar entre las últimas décadas del siglo XVIII y la mitad del siglo XIX, con una prolongación que llega al menos hasta finales del XIX, pues como veremos, un tipo de jaleos no se subsumieron en el nuevo estilo flamenco, sino que convivieron con él -con los bailes flamencos-durante todo el siglo XIX. De hecho, aunque la escuela flamenca fue ganando en popularidad y perdiéndola la de los bailes de jaleo, Pastora Imperio, Amalia Molina, Encarnación López y otras bailarinas o bailaoras, siguieron haciendo danzas teatrales de este tipo en el primer tercio del $\mathrm{XX}^{1}$.

\section{DEFINIENDO ESTILOS. LA ORIGINALIDAD DEL BAILE FLAMENCO}

Suele admitirse que a finales del siglo XIX el baile flamenco ya contaba con ciertos elementos distintivos: pasos, movimiento, modos expresivos que se habrían fraguado en la segunda mitad de siglo. Hasta la década de 1980 se destacó el papel que en esto habían jugado los cafés cantantes durante el último tercio del siglo XIX (BLAS VEGA, 1987). Pero la bibliografía posterior ha estudiado que el flamenco comenzó a manifestarse en otros espacios, previos a los cafés cantantes. Dejando de lado las que han sido retenidas como "prácticas preflamencas" antiguas (el modo de danzar y cantar de los gitanos, desde La Gitanilla de Cervantes hasta la fiesta descrita en Cartas Marruecas de Cadalso), esos espacios fueron las fiestas en casas particulares -al menos a partir de la década de 1830 , fiestas que podemos calificar ya de flamencas-; también las academias de baile desde la década de 1840-50 (ORTIZ NUEVO, 1990); y los teatros, antes de esas fechas y sobre todo después. Esos espacios jugaron un importante papel en la conformación del baile flamenco.

Dos constantes se repiten en las fuentes del siglo XIX sobre el primer baile flamenco: a) Nos lo presentan como un estilo en proceso de formación; b) Hacía uso de convenciones y terminología que remiten a otras tradiciones de baile y danza, populares y teatrales.

En efecto, las referencias al flamenco en esos espacios (fiestas particulares, academias, salones y teatros) nos lo muestran mezclado con todo tipo de bailes nacionales La muy citada narración del baile de candil al que asistió Charles Davillier en 1862 en una botillería de Triana, refleja una terminología y prácticas tremendamente abiertas: se describen en esa fiesta tiranas, rondeñas y malagueñas, canciones del tipo los Toros del Puerto... (DAVILLIER, 1982:

1 La primera danza registrada de la historia del cine, la de Carmen Dauset Carmencita (https://youtu.be/-15jwb1ZTMA), que data de 1894, es una de las versiones teatrales de este tipo de danzas. Lénica Reyes (2012) la ha identificado como una petenera. Esta danza fue en efecto muy popular en escenarios andaluces, particularmente desde 1854 hasta finales del siglo XIX. 
488-496). Si rondeñas y malagueñas aluden tanto a bailes de palillos como a cante flamenco, las tiranas y otras canciones aluden a las canciones de autor con las que se acompañaban los bailes de jaleo, principalmente los de ámbito teatral (vid. infra). Cantos populares de tipo tradicional, canción de autor inspirada en lo tradicional, bailes de palillos, de jaleo y flamencos al alimón. Por lo que se refiere a la sesión a que asistió en la academia de Luis Botella, así concluye Davillier su narración: "Ya en casa, creíamos oír durante toda la noche los jaleos, los boleros y todas las demás clases de bailes andaluces..." (DAVILLIER, 1982: 488). Se alternaron en esa sesión todos los bailes nacionales de un tipo u otro. Otros viajeros, como Pierre Laborde, Teófilo Gautier, Alejandro Dumas, Richard Ford, o españoles como Estébanez Calderón, dan trazas del mismo fenómeno, que continuó durante todo el siglo XIX.

Pero en medio de esa mescolanza, el baile flamenco iba configurando ciertas constantes. Vamos a delinear las que ya apuntaba desde sus primeras fases de desarrollo, para contrastarlas después con las de otras tradiciones dancísticas.

\section{RASGOS DEL PRIMER BAILE FLAMENCO}

El baile flamenco no destacó en su primera fase histórica por su perfección o complejidad técnica, sino por su carácter, por el poso, gracia, garbo y tronío con que se interpretaba (MARTÍNEZ DE LA PEÑA, 1969: 29). Casi todas las fuentes de entre 1840 hasta principios del XX, apuntan a que las bailaoras y bailaores no destacaban por su preparación técnica de conjunto, sino más bien por alguna habilidad particular, como la colocación del cuerpo, de los brazos, la técnica de los pies -mayormente en los hombres-... Y sobre todo por la expresión, la personalidad expresiva de cada quién.

Así Fernando el de Triana, testimonio directo de los ambientes flamencos de entre 1870 y 1930, dejó entre su amplio elenco de semblanzas de artistas, algunas apreciaciones de conjunto. La que sigue, sobre el baile flamenco de mujer, manifiesta qué se valoraba entre los propios artistas de entonces (la cursiva es nuestra): "El arte de bailar, en la mujer, ya sabemos que no es más que gracia en la figura, acompasados movimientos y un aire especial en la colocación de los brazos..." (FERNANDO EL DE TRIANA, 1986: 197).

Respecto al baile de hombre y su escaso despliegue de habilidades técnicas de cintura para arriba, dejó observaciones como la que sigue del bailaor Frasquillo:

"Por aquella época adolecía de lo que adolecen todos los bailadores, que en sus principios ejecutan mucho con los pies; pues el exceso de cuidado con éstos, les hace abandonar un tanto la colocación de los brazos..." (FERNANDO EL DE TRIANA, 1986: 164).
A Lamparilla -otro famoso bailaor de la época- lo califica de excepcional solo por la colocación de los brazos (FERNANDO EL DE TRIANA, 1986: 154). Y de Antonio el de Bilbao escribió: "En zapateao y alegrías ha sido el más grande, pero (...) era muy desigual, tenía tanta facilidad con los pies como diferencia artística de la cintura para arriba".

Una de las primeras caracterizaciones de conjunto del baile flamenco fue la de Benito Más y Prat. Publicada en La Ilustración Española y Americana en 1882 -aún reciente la incorporación del flamenco a los cafés cantantes-, su autor esboza el estilo flamenco de su época confrontándolo con el de otras dos tradiciones de baile: $1^{\circ}$ ) La de los bailes de palillos-que subdivide en otras dos: a) la vertiente popular de sevillanas, seguidillas y fandangos tipo malagueñas, y b) la vertiente teatral de el bolero, objeto principal de enseñanza de los maestros de danza. Y $2^{\circ}$ ) La de los bailes teatrales andaluces, es decir las versiones academizadas de las danzas o bailes de jaleo objeto principal de nuestro estudio. Así resume en sintética caracterización el estilo del baile flamenco:

Se baila generalmente por una persona sola; se acompaña con palmas y no se permiten saltos, trenzados ni batimanes $\left({ }^{2}\right)$; limitado al terreno que ha de recorrer, y predomina la línea recta en el movimiento (...). Pausado, cadencioso, eminentemente plástico y sensual (MÁS Y PRAT: 1882: 58).

También observó que el flamenco era la única tradición que cultivaba el baile a sólo de mujer y de hombre: de la mujer se valoraban su gracia, colocación y movimientos ondulantes, sobre todo el braceo. Del hombre, la precisión de su zapateado.

Cuando sale el uno, aplican el oído; cuando se levanta la otra, abren los ojos. Nótese aquí una nueva particularidad del flamenco, que rompe hasta cierto punto la tradición (...). El hombre y la mujer toman alternativamente turno en la danza (...). (MÁS Y PRAT, 1882: 59).

El "hasta cierto punto" salva el rigor de esta afirmación, pues conocemos antecedentes de danzas a sólo de hombre, particularmente el canario, cuya característica más destacada eran sus zapateados. En todo caso, el flamenco estaría retomando el carácter minoritario del baile de hombre a sólo en la tradición española. Por lo que se refiere a música acompañante, precisa: "Suprimidos los palillos, se hacen in-

2 "Movimiento que se hace alzando una pierna y llevándola rápidamente hacia la otra como para sacudirla" (Diccionario de la Lengua Española. R.A.E. Madrid, Espasa, 2014). 
dispensables las palmas y los cantes" (...). Y de la guitarra afirma que solo ella (...) "puede acompañar dignamente al sentido cante gitano y al baile flamenco" (MÁS Y PRAT, 1882: 59).

\section{ELEMENTOS COMPARTIDOS ENTRE BAILES FLAMENCOS Y JALEOS. PRIMERA APROXIMACIÓN}

Vemos apuntados desde fechas tempranas algunos de los rasgos del baile flamenco. A sólo, pausado, pegado al terreno, acompañado de palmas, cante y guitarra. El zapateado definía al baile de hombre, que movía escasamente los brazos salvo en cierres y careos. En el de mujer, aunque aparecían grupos de pies puntuales, destacaba la importancia expresiva de los brazos, juego de muñecas y manos, usando los chasquidos de los dedos y raramente castañuelas (Muy en menor grado que en los bailes de palillos, los boleros y los bailes de jaleo). Parece sugerirse ya la importancia de quiebros, desplantes, marcajes y remates. Puesto que tenía mucho de diálogo con el cante y la música (guitarra y percusión), estaría gestando ya el concepto de llamada, diálogo de la bailaora o bailaor con los músicos. Baile más reposado que el de las otras tradiciones dancísticas, evitaba los largos desplazamientos, herencia cierta de sus lugares "originarios": casas, tabernas, ventas o botillerías. Sobre la vestimenta, las iconografías de la época nos muestran el mantón en las bailaoras, el abanico y sombrero calañes -hasta los años 60-70, después se fue imponiendo el de ala ancha-. Y desde fines del siglo, la bata de cola.

Para formular la hipótesis de la conexión directa entre bailes de jaleo y bailes flamencos, basta reparar en unos pocos datos: los bailes de jaleo aparecen en las fuentes como la única tradición de danzas a sólo de mujer en Andalucía previa a la del flamenco; iban acompañados de cante y guitarra cuando se hacían en ambientes populares; el braceo jugaba también en ellos un papel expresivo clave -aunque unido casi siempre a los palillos-; en la vestimenta, también en los jaleos la bailadora popular o la bolera usaba el mantón, el sombrero, el abanico... Esos elementos raramente aparecían en los bailes de palillos. Convendrá por tanto detallar todo esto. Primero nos centraremos en los jaleos teatrales y después en los populares.

\section{ESPECIFICIDAD DE LOS BAILES DE JALEO}

¿Cómo eran considerados los bailes de jaleo en la segunda mitad del siglo XIX? El citado artículo de Más y Prat nos sirve como primera aproximación, aunque hay que precisar que él sólo analizó los teatrales, dejando de lado los que se hacían en ambientes populares. Por eso los llamó género teatral andaluz.

Para Más y Prat estas danzas, de las que cita expresamente el Ole, el Vito y el Jaleo de Jerez, conforman un estilo complementario de los "otros dos", el de palillos y el flamenco. Las caracteriza en su conjunto como una danza elaborada en la que la bailarina: "...salta, gira, se revuelve y agita los palillos en un compás más rápido y variado que el del puro flamenco, sus actitudes son plásticas y provocativas, y las formas se exteriorizan en violentos y estudiados escorzos" (MÁS Y PRAT, 1882: 59).

Descripción sintética pero precisa. Popularizados -afirma- a través de los carros del Corpus (teatro ambulante) y Corrales de Comedias, participan "de la voluptuosidad del flamenco y de la movilidad del de palillos" (Ibídem: 58). Otros autores repararon en esa mayor ligereza o movilidad de los jaleos respecto al flamenco, retenido en la época como lento y solemne. Rodríguez Marín contrastó el alegre y rápido jaleo andaluz con la melancólica y solemne soleá (RODRÍGUEZ MARÍN, 1929: 11). Y Machado y Álvarez los comparó aludiendo a "las alegrías andaluzas" y las "tristezas gitanas” (Machado y Álvarez, 1975: 13). Más y Prat también destaca que los jaleos se diferenciaban del género flamenco en que usaban las castañuelas; y del baile de palillos en que se bailaban por "una sola bolera o bailadora" (MÁS Y PRAT, 1882, 59).

Pero ya medio siglo antes los maestros Antonio Cairón y Carlo Blasis habían caracterizado estas danzas. Ambos mostraron bastantes coincidencias en cuanto a su descripción técnica, pero llamativas discrepancias en cuanto a su valoración personal.

\section{ZORONGO, HOLE, CACHUCHA... ZARABANDA CONTINUADA}

Hay un texto de Cecilia Böhl de Faber en La Gaviota (1849. Cap. XXI) que sirve de "pequeña historia del género" entre los años 1780 y 1840 aproximadamente, años en que fueron populares los bailes descritos por Cairón y Blasis, que vamos a comentar:

- ¿Te acuerdas, hermano, cuando cantábamos el zorongo y el trípili?

-¿Qué cosas son el zorongo y el tripili? -preguntó el barón a Rafael.

-Son -respondió- los progenitores del sereni, cachucha, y abuelos de la jaca de terciopelo, del vito y de otras canciones del día.

En efecto, Zorongo y Trípili, populares a fines del XVIII, dieron paso al Serení y a la Cachucha (principios del 
XIX), que a su vez cedieron en popularidad frente a el Vito en la década de 1840. Aunque Fernán Caballero los califica como "canciones", zorongo, cachucha y vito eran conocidas principalmente como danzas. El auge del Vito vino con la representación en Sevilla de El Tío Caniyitas o El Mundo Nuevo de Cádiz en 1849 y un año después, con enorme éxito, en Madrid. Esta zarzuela incorporaba el baile de el Vito, ya popular en Sevilla en los años 40 (PLAZA, 2012: 76).

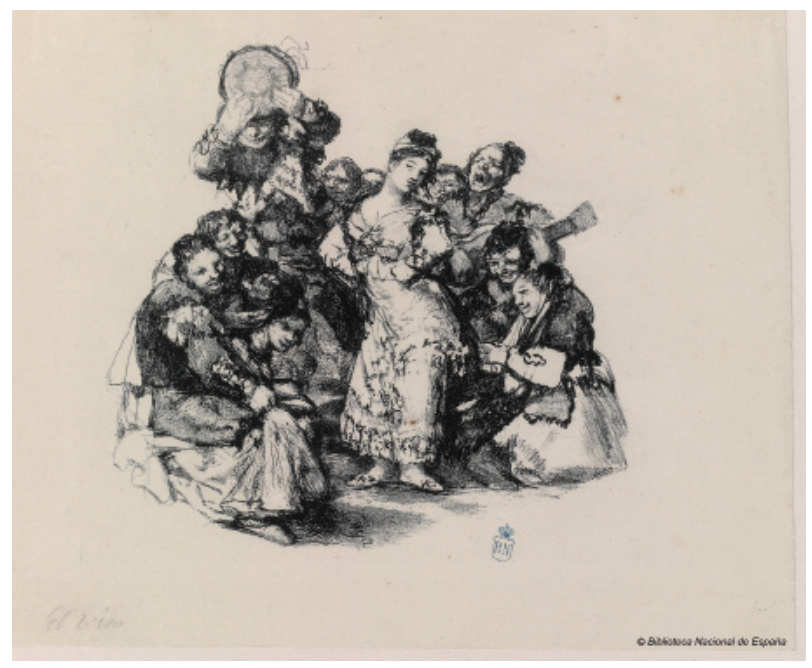

Imagen 01. El Vito. 1824-25. Autor: Francisco de Goya. Fuente: Biblioteca Digital Hispánica, BNM.

A pesar de la popularidad que estas danzas o bailes adquirieron desde fines del siglo XVIII, la tendencia que predominó entre los maestros españoles, al menos hasta mediado el siglo XIX, fue la de rechazo, quizá influidos por las ideas ilustradas. Así lo refleja el conocido texto de Antonio Cairón (1820) cuando alude a ciertos bailes de tipo "truanesco" de su tiempo, herederos de otros que se introdujeron en los teatros y cundieron en el pueblo, como pollo, rastrojo, guineo, gorrona...: "Todos eran parecidos unos a otros, y todos se bailaban con castañuelas; siendo siempre su compás ternario, y los movimientos de los pies y cuerpo retorcidos y descompuestos" (CAIRÓN, 1820: 101).

Al zorongo, el hole, la cachucha y otros, Cairón los considera copias de esas otras danzas más antiguas, y por ende como "zarabanda continuada". Matiza que "se bailan al capricho del maestro" sin necesidad de estudio o reglas, motivo por el que emite un juicio de rechazo, mezclando al parecer criterios técnicos y personales:
Son tan sencillos y de tan poca dificultad, que una mujer, aunque jamás haya bailado en su vida un paso de danza, ni sepa lo que ella es, basta que tenga un poco de gracia natural, para que inmediatamente sin dificultad pueda aprender en pocas lecciones cualquiera de los referidos bailes (CAIRÓN, 1820: 101-102).

Rechazo que apostilla con otra cita interesante para nosotros:

No constan (...) más que de media docena de movimientos (que ni siquiera se deben llamar pasos), unos rastreros y otros retorcidos que no sirven sino para deshacer lo que el estudio y las verdaderas reglas del baile mandan (...). Ninguno cuya idea fuese la de dedicarse al baile debería perder su tiempo en aprender semejantes bagatelas (CAIRÓN, 1820: 102).

Posicionamiento en favor del bolero y de rechazo de los jaleos por pícaros y rastreros. Dando por sentado sus orígenes populares, alude a su sometimiento a (pocas) reglas a cargo de maestros, que los enseñaban con éxito a condición de que la bailarina estuviera dotada de cierta gracia natural. Palabras que no ocultan el éxito de su práctica popular.

Muy distinta fue la opinión de Carlo Blasis, influyente maestro y coreógrafo italiano a principios del siglo XIX, quien en uno de sus tratados, el Manuel complet de la Danse publicado en 1830 en París ${ }^{3}$, refleja ya la popularización que los jaleos teatrales estaban alcanzando en Europa desde principios de siglo.

Aunque este maestro italiano reseña la importancia que aún conservaban el fandango y el bolero por esos años, lo interesante es que además de analizar las danzas españolas a sólo como grupo con entidad propia, lo considera el más característico de la época. No solo no las detesta, sino que se prodiga en alabanzas: las ve originales, variadas, elegantes: "il y a peu de danses étrangères qu'on puisse y comparer» ${ }^{4}$ (BLASIS, 1830: 35). Resalta el gusto y gracia con que vestían y actuaban las bailarinas españolas, a las que considera en esto insuperables, de fisonomía llamativa, de mirada expresiva... Todo en ellas, concluye, atraía al espectador.

En cuanto a danzas específicas, dedica unas líneas a la cachucha, la guaracha, el zapateado, el zorongo y el tripili

3 Consultada la versión francesa de 1830 en Google Books: https://books.google.es/books?id=mFa2IF7HtvQC\&printsec $=$ frontcov er\&hl=es\&source $=$ gbs ge summary $r \& c a d=0 \# v=$ onepage \&q\&f=fal se [Consulta 19. IV. 2014].

4 "Pocas danzas extranjeras se les pueden comparar". Está aludiendo a las estilizadas versiones teatrales que se estaban popularizando en Europa. 
trapala (todas, excepto la cachucha, del siglo XVIII). Dos coinciden con las nombradas por Cairón como "zarabanda continuada": el zorongo y la cachucha. De esta última obser- va que era danzada por un hombre o una mujer sola, aunque se adecuaba mejor a la mujer.

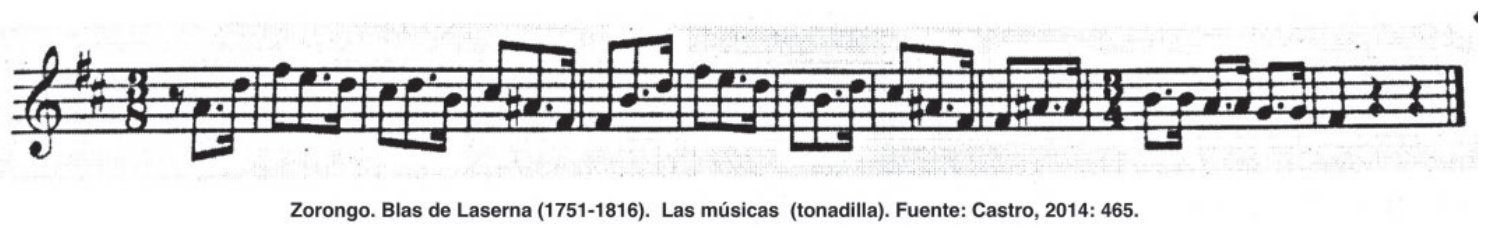

Imagen 02. El zorongo, partitura. Blas de Laserna. Fuente: Guillermo Castro, 2014.

Dejamos en notas a pie de página sus apreciaciones sobre la guaracha ${ }^{5}$, el zapateado ${ }^{6}$, el zorongo y el trípili trápala ${ }^{7}$. Lo que interesa resaltar aquí es que las notas que ve comunes a todas ellas (versiones teatrales de bailes a sólo, habitualmente de mujer; su ritmo ternario; uso de las castañuelas...) son similares a las que pocos años antes Cairón había descrito. Y además coinciden con los rasgos más citados de las danzas teatrales o mixtas del siglo XVII.

\section{DANZAS TEATRALES DE EXTRACCIÓN POPULAR. ANTECEDENTES HISTÓRICOS}

Ya en el último tercio del siglo XVI las danzas a sólo habían experimentado un primer florecimiento, especialmente en Andalucía y tierras americanas de influencia española. El ámbito del que más fuentes nos han quedado es el de los géneros breves representados en los intermedios de comedias, como "el entremés, la jácara, el baile dramático o la mojiganga, para el caso del teatro barroco" (RO-

5 De la guaracha detalla su compás ternario y que se danza por una persona acompañada de la guitarra, en ambientes teatrales. Práctica habitual en el teatro breve del siglo XVII pero que a finales del XVIII era un arcaísmo. Años más tarde Alejandro Laborde la describió ejecutada por una sola persona y acompañada de guitarra (Plaza, 1999: 163). Se cita como muy similar al zapateado, y derivada del antiguo canario. De hecho con frecuencia ambos nombres, guaracha y zapateado, parecen aludir a un mismo tipo de baile (Roldán, 2015: 80).

6 Del zapateado observa tener el mismo movimiento que la guaracha, en $3 / 8$, que se acompaña de guitarra, pandero y castañuelas y que hay en él mucho ruido hecho por los pies: sus pasos son frappés (zapateados). Añadamos que en 1806 se bailó en Sevilla en una función teatral de beneficio como baile gitano poco elaborado pero expresivo (Plaza, 1999). Charles Davillier lo describió en 1862 como baile especialmente vivo pero de escasa elaboración.

7 Detalla del zorongo sus pasos simples hacia delante y hacia atrás, batiendo a veces las medidas con las manos. Y del tripili trapala su semejanza con el zorongo aunque con diferente cierre.
MERO FERRER, 2008: 241). Las fuentes hacen continuas referencias, directas o indirectas, al origen popular de estas danzas.

En esas piezas breves, ciertos bayles o danzas de cascabel (de tradición popular), se adaptaron hasta dar origen a danzas que autores como Diez Borque, Moreno Muñoz o Aurelio Capmany llaman mixtas en alusión a sus raíces populares y a su reelaboración y arreglo para su representación teatral (MORENO MUÑOZ, 2008: 92-98), adaptación llevada a cabo por actrices, cómicas, músicos o maestros de danza. Zarabandas, chaconas, jácaras, o canarios (entre otras) fueron muy populares y ciertos rasgos compartidos coinciden con los que más tarde encontramos en los bailes de jaleo.

La abundancia de juegos de punta y tacón, batidas rápidas de pies o zapateados, eran característicos de los canarios, lo que se corresponde con las abundantes figuraciones rítmicas en tresillos y tempo rápido que se observa en las fuentes musicales y teatrales (ESSES, 1994). Sabemos de canarios desde finales del siglo XVI, a veces citado como baile popular a sólo, normalmente de hombre, otras como danza teatral o cortesana en versiones de pareja. Sobre su adaptación a las tablas o a ámbitos aristocráticos, Flórez lo documenta en versiones tempranas de pareja, realizadas por maestros italianos y franceses, en las que se pone el énfasis en el cortejo amoroso. Desde finales del siglo XVII el canario quedó relegado a versiones populares (FLÓREZ, 2006: 54) y ya en el XVIII todo indica que sus pasos reaparecen en danzas como la guaracha y el zapateado.

Por su parte la zarabanda ha sido la danza más citada como principal predecesora de los posteriores bailes de jaleo. De carácter sensual, tachada de indecente -en sus primeras versiones populares- por muchos autores de la época, para Ruiz Mayordomo es, junto con la jácara, "el máximo exponente coreográfico del género femenino; ningún otro 
tipo de danza o baile teatral es asociado en exclusividad a las mujeres" (En FLÓREZ, 2006: 64).

Muchos textos describieron la zarabanda como baile popular y sensual. Así Covarrubias, que la define como baile muy conocido en su época (la cursiva es nuestra):

Es alegre y lascivo porque se hace con meneos del cuerpo descompuestos (...). Aunque se mueven con todas las partes del cuerpo, los brazos hacen los más ademanes, sonando las castañetas (...) la que baile la zarabanda cierne con el cuerpo a una parte y a otra, y va rodeando el teatro o lugar donde baile..." (Tesoro, 984, en FLÓREZ, 2006: 63$)^{8}$.

Marie Catherine D'Aulnoy (1691) escribió haberla presenciado en el teatro como danza de mujer en la que las castañuelas o palillos jugaban un papel central:

Los entreactos estaban mezclados con danzas al son de arpas y de guitarras. Las comediantas llevaban castañuelas y un sombrerito; es la costumbre cuando bailan; y cuando es la zarabanda (...) mueven demasiado sus brazos, pasan a menudo la mano sobre su sombrero y sobre su rostro, con una cierta gracia (...); tocan admirablemente bien las castañuelas. (D'AULNOY, 1986: 62).

Muchas fuentes musicales nos muestran en estas danzas mixtas el rasgo común de sus ritmos ternarios estructurados en ciclos rítmico-armónicos de 6 o 12 tiempos en hemiolia y con frecuentes comienzos anacrúsicos (ESSES, 1994). En cuanto a las sonoridades, a caballo entre lo tonal y lo modal, remitimos a otros estudios (ARRIAGA, 2014; BERLANGA, 2015; MANUEL, 2002; VALDIVIA, 2015). Otras fuentes aluden al trasvase de tonadas y danzas desde ámbitos "populares" al teatro en versiones adaptadas, donde adquirían nueva popularidad y volvían al pueblo renovadas (FLÓREZ, 2006; MORENO MUÑOZ, 2008). Esto explica la ambigüedad de su designación, unas veces como bailes (populares) y otras como danzas aristocráticas, otra coincidencia con los posteriores jaleos.

Hasta aquí nuestro paseo por los jaleos teatrales y los que consideramos sus más que probables precedentes. Pero nuestra hipótesis afirma que fueron los jaleos practicados en ambientes populares los que sufrieron una primera transformación o aflamencamiento, así que debemos detenernos en ellos.

8 También para Cano y Urreta, su gracia estribaba "en gestos y movimientos de manos" (Días de Jardín, 1617). Cano y Urreta, Alonso. Días de Jardín. En Lenir, 14, 2014, p. 308. http://parnaseo.uv.es/ Lemir/Revista/Revista18/Textos/03 Dias de jardin Alonso Cano.pdf [Consulta: 15. III. 2016].

\section{JALEOS POPULARES. UN PASEO POR LA PRÁCTICA DEL SIGLO XIX}

El término baile de jaleo en la primera mitad del siglo XIX no aludía a una categoría del todo definida, cerrada. $\mathrm{Ni}$ era el único término usado para designar las danzas que estamos estudiando. Pero sí fue habitual, al menos en los ambientes populares, como nos disponemos a ver. El Diccionario analítico de todas las palabras castellanas que pueden tener en la oración diferente significado, de Félix Massip y Moyá (1866), lo define así:

Jaleo:

-Sustantivo masculino. Acción y efecto de jalear. v.gr. "Más alegra el jaleo que la danza".

-También sustantivo masculino: Diversión de gente ordinaria. Más vale la franqueza de un jaleo pobre que la etiqueta de la alta sociedad.

-Primera persona del presente de indicativo del verbo jalear. V.gr.: Por más que jaleo el perro viejo, no quiere correr.

Se dibujan dos significados principales. Uno: el de animar la danza (con cante, palmas, gritos de ánimo, aclamaciones y piropos). El otro: reunión festiva con baile, de gente de condición humilde. Ambos están relacionados y parecen indicar que el uso coloquial de jalear (animar en el baile, sobre todo a la bailaora, secundariamente al bailaor y a la pareja de baile), parece estar en el origen de la expresión bailes de jaleo.

En "Un baile de candil", José $\mathrm{M}^{\mathrm{a}}$ Gutiérrez de Alba describe el momento de la aparición, de un baile a sólo de mujer, al que llama precisamente el Jaleo. En esas fiestas, entre baile y baile de pareja, tipo malagueñas a compás (fandangos) o sevillanas, como intermedios más o menos espontáneos aparecían los jaleos. (La cursiva es nuestra):

¿Qué se canta? El Jaleo, y que lo baile esa moza que tiene la sal de las sales en ese cuerpo sandunguero. Esto dicen dirigiéndose a una moza morena de ojos negros y garboso talle. Que lo baile, repiten varias voces; y la moza, dirigiendo una mirada de fuego y una sonrisa suplicante a un terne, que con el calañés sobre el ojo la contempla: cántame tú, Pepillo, le dice; y sin aguardar otra invitación, toma la guitarra, y al compás de un cadencioso rasgueo, que la moza sigue con sus movimientos voluptuosos, canta con voz firme y sonora ésta u otra copla (...): En medio de mis fatigas / por vivir quise dormirme; / Que el que vive como yo, / cuando duerme es cuando vive. Y las palmas suenan, y sigue el jaleo, y el mozo hace resonar las cuerdas de la guitarra... (GUTIÉRREZ DE ALBA, ca 1870: 26). 
El texto forma parte de la narración de una de esas fiestas vecinales, no de una función flamenca (estas últimas destacan por la presencia significativa de gitanos y por la llegada de "gente de fuera" que pagaba o incluso financiaba el evento, introduciéndose un elemento de profesionalización ajeno a los bailes de candil tradicionales). Con el término "ésta u otra copla", el autor alude a coplas a sólo, que con frecuencia eran improvisadas. Se refleja la habitual práctica de su acompañamiento con guitarra rasgueada. El jaleo se canta y se baila. Y las coplas de jaleo son coplas de bailes de jaleo, que casi siempre se asociaba al baile a sólo de mujer. Consideramos importante retener este concepto de jaleo, como categoría de un tipo de danzas y no -como en ámbitos de la flamencología se ha sugerido- como un "cierto baile andaluz de caracteres no del todo bien conocidos", del que se apunta que pudiera haber sido precedente de ciertos bailes flamencos, particularmente de las bulerías. Así por ejemplo José Luis Navarro (2008: 187 y ss.), si bien ha aportado interesantes datos sobre muchos jaleos y sugerido que fueron precedentes del baile flamenco, no llega a definir la categoría bailes de jaleo o jaleos.

Bien explícita es la referencia del francés Émile Guimet, quien viajó por buena parte de España en 1862 y presenció un jaleo en Sevilla -donde ya abundaban las funciones de "bailes del país" para turistas-, tras cuya representación preguntó de qué baile se trataba. La misma bailaora le respondió que era un jaleo gitano, y que los había de otros tipos (después presenció lo que le fue explicado como el "jaleo del torero"). He aquí la certera descripción que Guimet hizo de el jaleo en pocas palabras:

Et le Jaléo! (...). Une danseuse seule, non plus accompagnée du violon et des castagnettes, mais d'un chanteur, d'une guitare et des mains de tous les spectateurs qui marquent le rythme en frappant. (GUIMET, 1862: $239-40)^{9}$.

Una representación de un baile a sólo de una bailarina jaleada por un cantaor que toca a la vez las palmas (más el habitual acompañamiento a la guitarra), la tenemos en Jaleando a la puerta del cortijo, cuadro de Manuel Cabral Aguado Bejarano datado en 1854.

9 "El jaleo! (...). Una bailarina sola sin más acompañamiento que el violín y las castañuelas, un cantante, una guitarra y las manos de todos los espectadores que marcan el ritmo tocando las palmas".

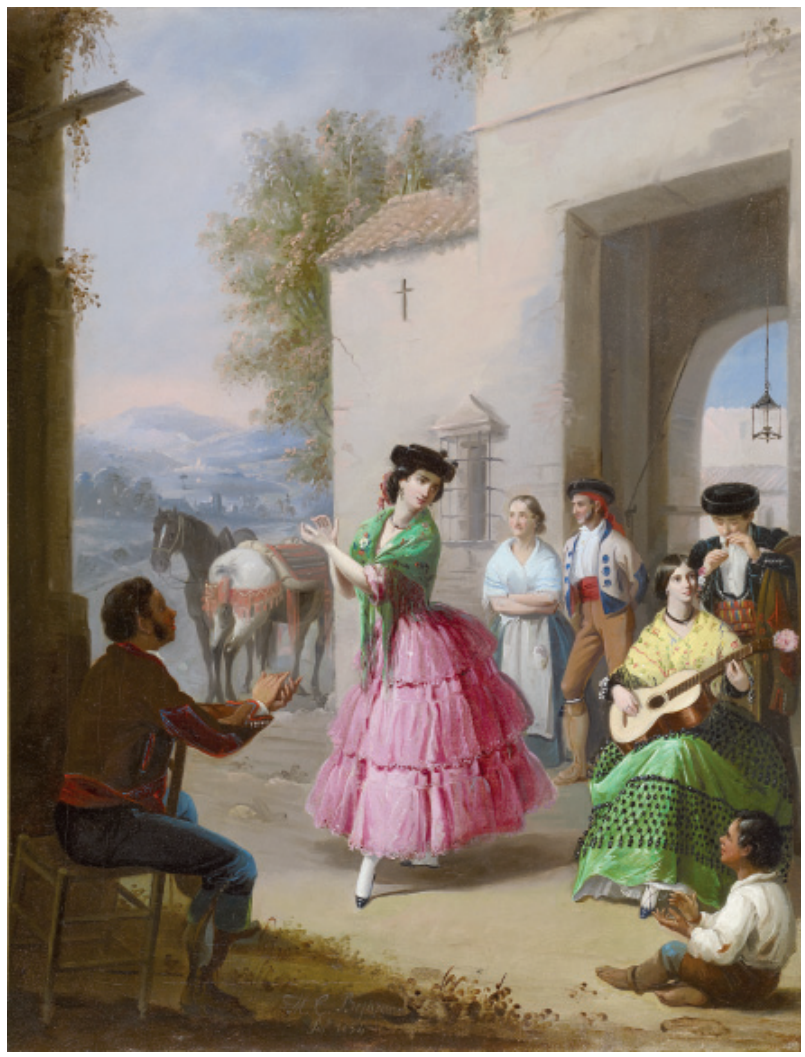

Imagen 03. Manuel Cabral Aguado Bejarano. Jaleando a la puerta del cortijo, 1854. Óleo sobre lienzo, 64 x $50 \mathrm{~cm}$. Fuente y (C) Colección Carmen Thyssen-Bornemisza en préstamo gratuito al Museo Carmen Thyssen Málaga.

\section{UN JALEO MUY POPULAR EN LA PRIMERA MITAD DEL SIGLO XIX: EL OLE}

El Ole (con frecuencia sin acento en la $e$ ) es uno de los bailes de jaleo más citados en el siglo XIX. Sus primeras referencias nos remiten a las ciudades de Cádiz y Sevilla: El Diario Mercantil, Cádiz, 7. II. $1803^{10}$, el Ole en Más y Prat, 1882, el "jaleo denominado El Ole" en el diario El Porvenir, Sevilla, 26. III. 1897... También Cairón (1820) hace referencia a el hole. Interesa resaltar que las fuentes de la primera mitad del siglo lo describen sobre todo en ambientes populares. Rocío Plaza (1999: 164) lo ha señalado para el caso de Sevilla: El Olé apareció muy poco en las tablas en la primera

10 Citado por Faustino Núñez en: Flamencópolis, http://www. flamencopolis.com/archives/3348. [Consulta 12 III. 2016]. 
mitad de siglo, pero fue popular en fiestas privadas. Conjugando datos de fuentes de la época, destaca los siguientes rasgos de este baile:

La flexibilidad en el cuerpo y la desenvoltura de movimientos de la bailarina como elementos más preciados y los contrastes entre momentos de quietud total, como si cayera en una especie de éxtasis y el rápido despertar en un movimiento eléctrico y súbito (...). Siempre sería solicitado para una mujer sola (PLAZA, 1999:164).

Una referencia al Ole se encuentra en las escenas trianeras publicadas en 1812/13 en el periódico sevillano El Tío Tremenda o los Críticos del Malecón. Ortiz Nuevo las recoge en su ya citado libro. A propósito de lo que se cantó y bailó en un jaleillo pobre improvisado por gente del barrio -probablemente gitanos- para obsequiar a un general, aparece una conversación entre dos vecinos:

-Podrío. Maldita sea el alma del vino mal vebío! Que me perdiera yo ese güen rato! Vamos a elante: infórmeme usté de lo que se jizo.

Tremenda. Qué se había de jacer? Cantar ca uno lo que puo de repente, y de la moa que supo. Se cantó la caña, la picaresca o el ole; la canción de España de la guerra; acomoándole otra letra al intento; y por fin se entretuvo el rato.

Podrío. Y no más que eso?

Epidemia. Pos qué quería usté más? Habíamos de haber cantao algunas arias o algunos villancicos que se riyera la gente? (ORTIZ NUEVO, 1990: 22).

En otro pasaje se vuelve al argumento: Si hubieran dío cantando décimas y sonetos y arias y villancicos, ¿no sería eso un disparate? (...); tan propia de aquellos probes fue aquella alabanza como nuestra caña y nuestro ole entre nosotros (ORTIZ NUEVO 1990: 25).

También Richard Ford en su conocida crónica sobre su estancia en España entre los años 1830 a 33, reseñó el Olé al describir las funciones de baile con protagonismo especial de gitanos en el barrio de Triana, que podemos retener como ya flamencas. Para Ford, el Olé pertenecía a un tipo de danzas "más notables por la energía que por la gracia y no tienen en ellas menos trabajo las piernas que todo el cuerpo, las caderas y los brazos" (FORD, 1988: 357). Así caracteriza el ambiente en que aparecían:

La escena del baile es generalmente el barrio de Triana, que viene a ser el Trastevere de la ciudad y cueva de toreros, contrabandistas, pilletes y gitanos, cuyas mujeres son las premières danseuses en estas ocasiones, en las que los hombres nunca intervienen (...).

El baile, que es muy semejante al ghowasee de los egipcios y al nautch de los indios, se llama el olé entre los españoles y el romalís entre sus gitanos; el alma y la esencia de él consiste en la expresión de cierto sentimiento, que no es ciertamente de carácter muy sentimental o correcto. Las mujeres, que parecen no tener huesos, resuelven el problema del movimiento continuo disfrutando sus pies relativamente de un privilegio, pues todo el cuerpo toma parte en la pantomima y tiembla como la hoja del álamo; la flexibilidad y la figura de Terpsícore de una joven andaluza, sea gitana o no, ha sido designada (...). (FORD, 1988: 356-357).

Antes que Ford, el francés Alexander Laborde hizo referencia al olle, junto a las guarachas y el cachirulo, como danza andaluza de mujer de clase inferior. Tras unos párrafos dedicados a las "danzas nacionales" (seguidilla, bolero y fandango), escribe sobre ciertas danzas que pudo haber visto en Cádiz y llama explícitamente "del pueblo":

Mais rien dans ce genre n'est aussi extraordinaire que certaines danses du peuple, qui ont quelque chose de plus voluptueux et de sauvage à-la-fois: c'est l'olle et le cachirulo, espèces de danses lubriques, qui rappellent ce que les voyageurs rapportent des danses nègres et africaines" (...). Les femmes y marquent la mesure avec le talon; elles le font avec une rare précision; ce mouvement, qui paraît devoir être indifférent, leur donne une grâce nouvelle". (LABORDE, 1808/1834: 405$406)^{11}$.

Además de las referencias a su carácter de baile pegado a tierra (marcan el compás con el talón), su opinión sobre su extracción popular es clara: "Estas danzas en general no están en uso en la buena sociedad. Las damas españolas no las necesitan para complacer, las dejan a las mujeres de clase inferior" (Ibídem).

11 "Pero no hay nada más extraordinario en este género que ciertas danzas del pueblo que tienen algo de voluptuoso y de salvaje a la vez: el olle y el cachirulo, especie de danzas lúbricas que recuerdan lo que los viajeros describen de las danzas de negros y africanos (...). Las mujeres marcan el compás con el talón y lo hacen con una rara precisión. Movimiento que parecería indiferente pero que les da una gracia especial". Esta fuente la tomamos con reservas, pues no contamos con la certeza de que Laborde las presenciara personalmente: algunos datos los sacó de libros sobre danza de la época. Edición consultada: Itinéraire descriptif de l'Espagne, $3^{\text {a }}$ edición en francés, 1834. En https://books.google.es/books?id=DA5hHulsx $-\mathrm{gC} \& \mathrm{pg}=\mathrm{PA} 406 \& \mathrm{dq}=$ alexandre+laborde + cachirulo $\& \mathrm{hl}=\mathrm{es} \& \mathrm{sa}=\mathrm{X} \&$ redir $\mathrm{esc}=\mathrm{y} \# \mathrm{v}=$ onepage $\& \mathrm{q}=$ alexandre $\% 20$ laborde\%20cachirulo\&f=false [Consultada 15. III. 2016). 


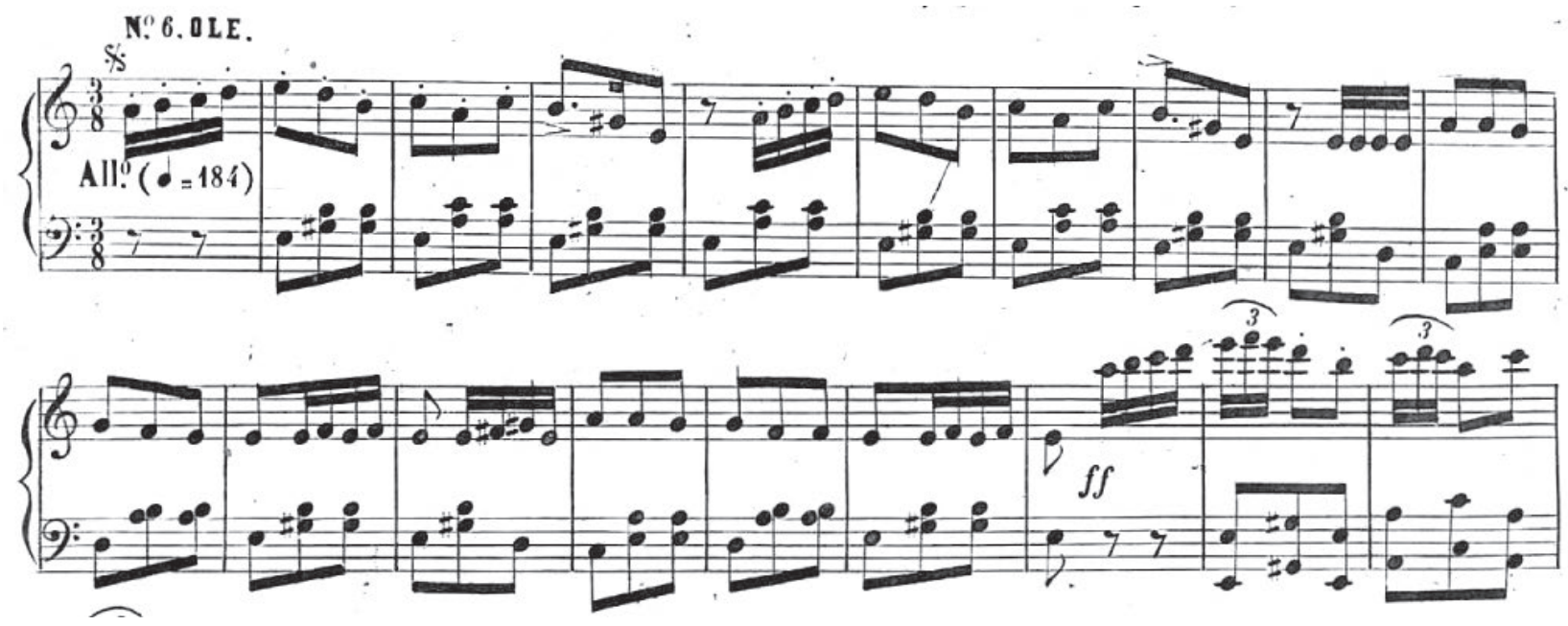

Imagen 04. El Olé. Autor: Juan Cansino (La Joya de Andalucía, 1865).

Fuente: Biblioteca Digital Hispánica, BNE, MP/1807/22

La litografía sobre el Ole que adjuntamos, probablemente de principios de siglo - no fechada con exactitud- parece reflejar esos ambientes de los jaleos pobres o bailes de candil en los que estas danzas hacían su aparición.

El Olé contó con muchas versiones académicas. En algunas de ellas creemos encontrar ese aire popular que lo caracterizó. Así lo describe Más y Prat, aun precisando que contaba con "variantes infinitas":

El capricho o habilidad de la bolera se prolonga indefinidamente. La bailarina hinca la rodilla, parece desmayarse y logra tocar con el hombro el suelo con música lenta, especie de letargo voluptuoso, del que la bolera despierta para volver a sus rápidos giros (MÁS Y PRAT, 1882: 59).

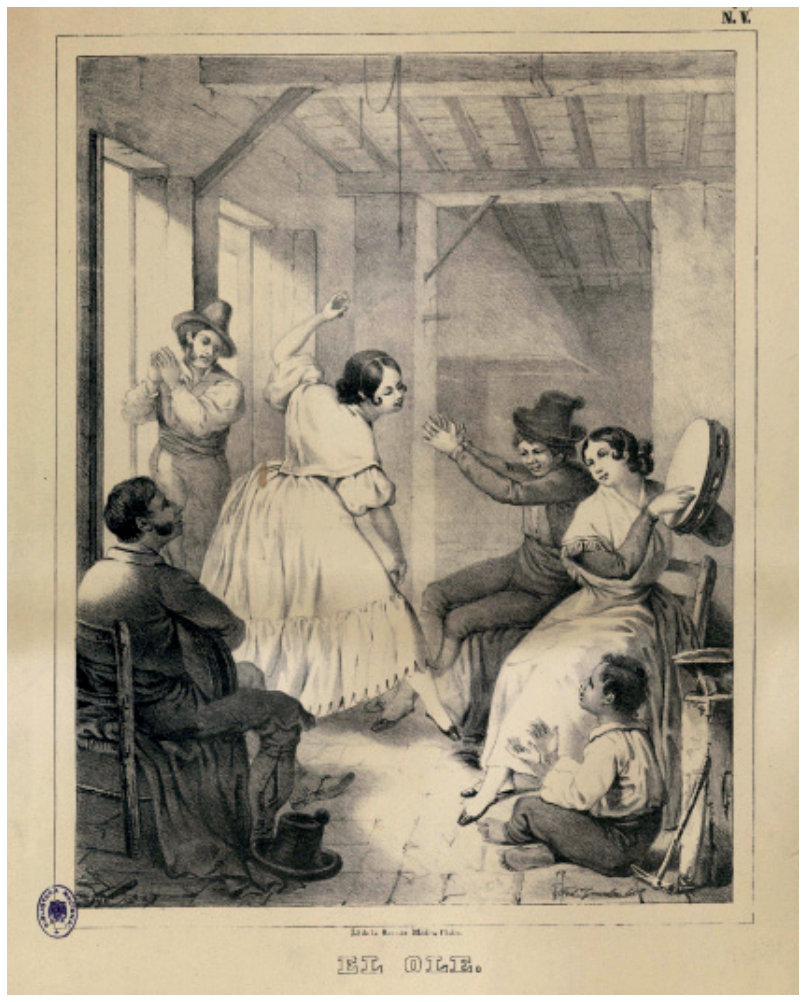

Imagen 05. El olé. Federico González. Fuente: Biblioteca Digital Hispánica, BNE: Invent/27877. Litografía de la Sociedad de la Revista Médica de Cádiz. 
Deberemos aludir, aunque sea brevemente, a los bailes boleros de pareja, cuyo referente histórico más conocido es el bolero, y a sus relaciones y diferencias con los jaleos y los populares bailes de palillos, expresión con la que se designaba en Andalucía a los de pareja, fueran éstos populares (sevillanas o seguidillas sevillanas y fandangos del sur tipo malagueñas) o boleros academizados.

\section{LOS BAILES NACIONALES}

La tradición bolera, al menos la más ortodoxa, ha sido considerada como "nuestra versión" del ballet europeo, mezcla entre el ballet clásico y romántico (el ballet d'action) y determinados bailes españoles de extracción popular. Entendemos que hay datos que conducen a pensar que ya desde la época de primer auge de los bailes nacionales (en torno a 1780-90), se decantaron dos tendencias:

a) Una más académica, refinada y técnica, la del bolero propiamente dicho, baile de pareja academizado, principal referente de la escuela clásica de baile español. Su paradigma musical, el aire o son al que se bailaban mayoritariamente, fueron las seguidillas boleras. Autores como José Gelardo, ven que la componente de ballet europeo se impuso sobre los referentes nacionales, resultando "una paulatina tendencia hacia la occidentalización de sus formas, pasos, técnicas, etc." (GELARDO, 2013).

b) De esta tendencia parecen haberse sustraído los jaleos, cuyo auge a finales del siglo XVIII tuvo mucho de fenómeno popular ajeno a opiniones como la citada del maestro Cairón. Como veremos, los jaleos (sobre todo los teatrales o de salón) no se bailaban al son de seguidillas boleras sino de tiranas, canciones andaluzas que se explican bien como el trasunto más o menos logrado de las coplas -con frecuencia improvisadas- de los jaleos populares.
Los estudios sobre el baile español han prestado poca atención a esta polarización. Sí se ha estudiado el auge que los bailes nacionales cobraron a finales de siglo XVIII en los teatros españoles al hilo del Real decreto de 1799 que prohibió la representación de bailes extranjeros. Cristina Roldán ha documentado que en los primeros años del siglo XIX duplicaron su presencia en los teatros de Madrid (ROLDÁN, 2015: 51). Guadalupe Mera (MARTÍNEZ DEL FRESNO ed., 2011: 174 y ss.) ha estudiado con rigor la división de posturas entre los ilustrados de final de siglo, a favor o en contra de bailes nacionales y bailes extranjeros, principalmente el baile de acción. Pero no entra en esta polarización de tendencias en el seno del mismo baile español.

Sabemos que hasta aproximadamente la década de 1820 o 30, los más ortodoxos boleros se mantenían en las tablas por encima de los bailes a sólo. Así en la prensa gaditana de 1813, predominan los boleros (a veces intermediados con cachucha), pero hay ya continuas referencias a bailes a sólo, destacando la cachucha, el zapateado, la guaracha y el ole (BRAVO LIÑÁN, 1993: 7-42). Pero en la década de los 40 el auge de los jaleos acabó por desbancar a los boleros en muchos espacios.

Un texto de 1797 de Juan Jacinto Rodríguez Calderón, en que se narra el éxito de Mariana Márquez con su zorongo en el Coliseo de Madrid en 1795, lo retenemos como un primer momento en que afloró ya cierta competencia: El bien asentado bolero sufrió un embate a cargo del Zorongo "que tanto ruido hizo en la Corte cuando la inimitable (en este género de Xácaras) Mariana Márquez lo cantó y bailó en el Coliseo del Príncipe" (RODRÍGUEZ CALDERÓN, 1807: 26-27). Es significativo que Estébanez Calderón lo recordara medio siglo después: la Márquez habría puesto con su zorongo "en gran conflicto y en peligroso trance al Bolero, pero éste triunfó". Hoy sabemos que ese triunfo no se mantuvo por mucho tiempo, pues en las fechas en que El Solitario escribía (1846), el bolero ya no eran la moda, entre tanto que los jaleos estaban alcanzando su momento de gloria. 


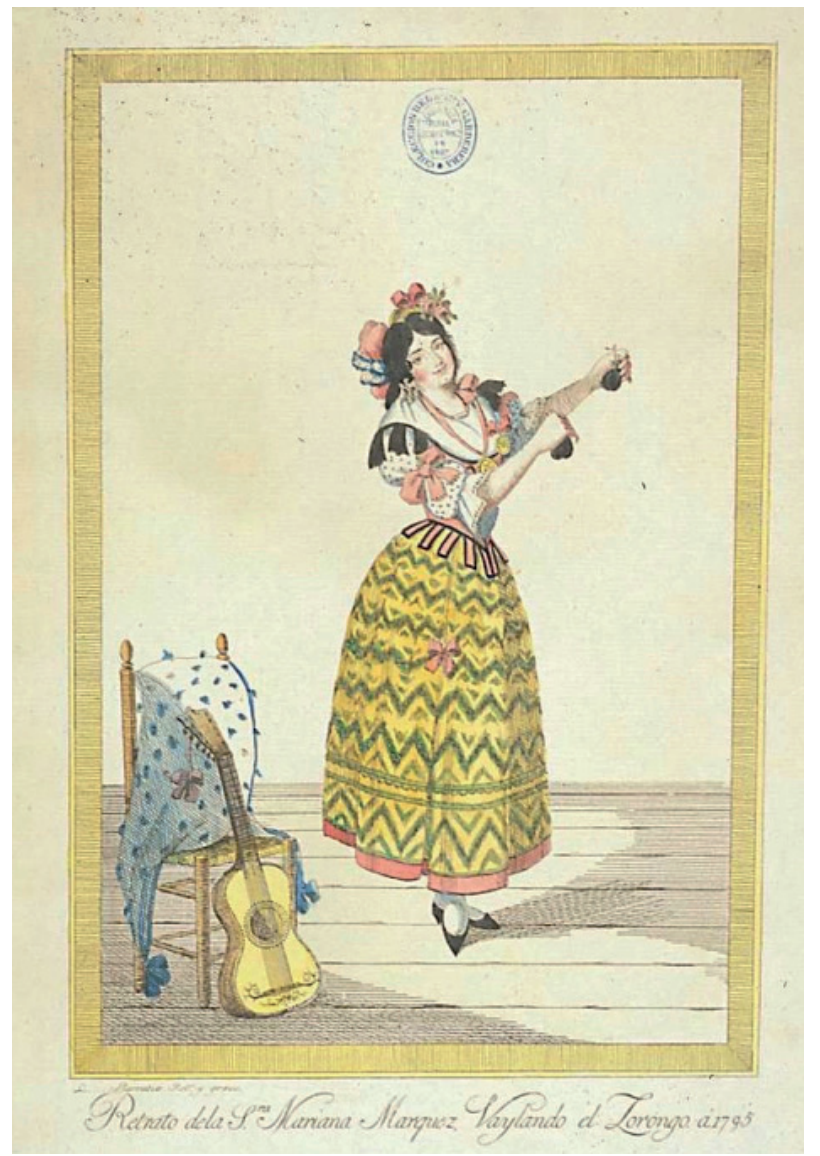

Imagen 06. Retrato de Mariana Márquez bailando el zorongo.

Madrid, col. del teatro del Príncipe, 1795.

Fuente: Biblioteca Digital Hispánica, BNE, IH/5437

Fueron años de especial fervor casticista. Faustino Núñez ${ }^{12}$ ha comentado una crónica periodística madrileña (El Español, 1847), cuyo autor lamenta el afrancesamiento del bolero y reprueba el estilo que el señor Vera, maestro y director de danzas, imprimió a su espectáculo de bailes españoles. Se califica al Sr. Vera como "uno de lo boleros que más conspiran contra nuestros bailes nacionales" ${ }^{13}$. Núñez concluye que esa estilización y afrancesamiento del bolero

12 NÚÑEZ, Faustino. El afinador de noticias. http://elafinadordenoticias.blogspot.com.es/2012/07/cuando-el-bolero-se-hizo-flamenco.html. Consulta: 19. IV. 2015. pañolas.

13 Aquí la palabra bolero es usada como maestro de danzas es- habría continuado hasta la actualidad. Y que tal estado de opinión casticista de mediados de siglo propició el aflorar del flamenco.

Seguiremos viendo, a propósito de las tiranas, que considerar baile bolero, sin más especificaciones, a los bailes de jaleo, conlleva cierta simplificación, pues aunque éstos contaran con versiones académicas bailadas por bailarinas boleras, tenían características específicas, distintivas.

\section{LAS TIRANAS, LA MÚSICA DE LOS JALEOS}

Bajo el nombre de tirana se designaba a un tipo genérico de canciones de autor, con letras de carácter picaresco y jocoso, aptas para el baile teatral, de origen y conexiones vagamente andaluzas. La relación de las tiranas con el baile no ha sido bien esclarecida en la bibliografía. Pero todo indica que se popularizaron en las tonadillas, ya ligadas al baile, y más tarde como música de números sueltos de baile en intermedios teatrales.

Así Celsa Alonso caracteriza a las tiranas como aire de danza frecuente en el teatro tonadillero (ALONSO 1999: 65-70). Don Preciso las definió justamente como género de canción bailable, cuya popularidad creció por los años de 1770-80: "al paso que se cantaban con coplillas de a cuatro versos asonantados de ocho sílabas, se bailaban con un compás claro y demarcado" (IZA ZAMÁCOLA, 1982, 14-15). Eduardo Ocón (1888) escribió que fueron en su origen aires de baile y canto, aunque poco a poco fueron conociéndose como canciones. Por su parte Núñez señala la abundancia de los compases en $3 / 8$ en este género ${ }^{14}$. Y matiza que "es canto y es baile". Y es que aunque también se cantaron sin baile, las tiranas pueden ser retenidas como la parte musical de bailes de jaleo, en el teatro breve y en los salones aristocráticos y burgueses. Si a partir de las últimas décadas del siglo XVIII comenzaron a compartir popularidad con las seguidillas boleras, fue precisamente por el auge que estaban adquiriendo los jaleos teatrales en su función de bailes epilogales.

Algunos de los datos que sobre los jaleos han sacado a la luz Faustino Núñez y Guillermo Castro, adquieren nueva luz si los enmarcamos en la polarización de tendencias boleros/jaleos y en la hipótesis según la cuál las tiranas fueron el nombre genérico de la música que acompañaba a los jaleos.

Así en un texto de 1831 (en ALONSO, 1998: 90), leemos que en cierto momento de un recital que Vicenta Michans de Dot ofreció a los reyes en Palacio acompañada al piano por Mariano Lidón, ella cantó acompañada de la

14 http://elafinadordenoticias.blogspot.com.es/search/label/1790. [Consulta: 19. IV 2015]. 
guitarra El serení de los ciegos, El Requiebro, El Za-pili, El lelé, El Alzapilili y El Puente. Tras un intermedio, el rey "la hizo repetir algunos de los jaleos que antes había cantado a la guitarra...". En el texto se llama jaleos a las tiranas recién interpretadas. Otra "sorpresa" que se resuelve es la reseñada por Cristina Roldán, quien al localizar en la Biblioteca Histórica de Madrid las particellas de un manuscrito musical catalogado como "Jaleo de gitanos" (BHM, Mus 627-637), vio en la primera página de este manuscrito que "en realidad es una Tirana" (Roldán, 2015: 83).

También se iluminan textos de la época que contraponen no ya los boleros con los jaleos, sino los boleros con las tiranas. Así la copla reseñada por Núñez, de una tonadilla de 1790, en la que se confrontan las mudanzas del bolero a los meneos de la tirana aludiendo a una cierta "rivalidad":

Ya hubiera de la tirana logrado el fin el bolero si sus mudanzas picaran lo que de ella los meneos.

Y otra referencia, esta vez de la tonadilla La maja de la Cinga:

En posesión del volero / se mira por toda España, mas está con mil recelos / que han de olvidarlo mañana porque ya ay noticias / de que la tirana muy fijo se dize / que en Yndias se halla ha escrito que vuelve / y el bolero anda con estos temores / diciendo con gracia:

\section{$(\ldots)$}

tú vuelve tiranita / no te tardes más porque ya el bolero / nos llega a enfadar $(\ldots)^{15}$.

Para Guillermo Castro (2013), piezas como El serení de los ciegos, El Requiebro, El Za-Pii, El Lelé... El Caram$b a \ldots$ (tiranas) se pueden calificar como jaleos, al menos los que eran cantados a la guitarra, aunque no fueran piezas de musicalidad flamenca, sino canciones andaluzas de moda, orientadas a su cultivo en salones y teatros. Coincidimos con él, añadiendo que en efecto, no tienen por qué ser cante flamenco, eran canciones, la parte musical de ciertos bailes de jaleo academizados. Canciones que conforme entraba el siglo XIX fueron siendo conocidas como andaluzas. En resumen, concluimos que "la tirana" no sería el antecedente

15 Núñez, op. cit. perfecto "del jaleo", pues más que dos géneros separables (salvo conceptualmente), eran las dos caras de una misma moneda. Guarachas, zapateados, zorongos, trípili-trápala, etc., eran genéricamente designados como tiranas -en alusión a la música- y como jaleos en alusión al baile correspondiente.

Por lo que se refiere a las coplas de los jaleos populares (las que luego adquirieron más carácter flamenco), eran citadas con cierta frecuencia -cuando se las designaba de modo genérico- como coplas de jaleo. El guitarrista Rafael Marín (1902: 176) testimonia restos de esa terminología en ambientes flamencos todavía a principios de siglo XX. Todo indica que los "jaleos flamencos" fueron reposando el compás y adquiriendo un carácter más solemne. Así entendemos a Rodríguez Marín cuando escribió que en torno a mediados del siglo (XIX) en las reuniones de aficionados "el alegre jaleo, puramente andaluz, y la melancólica soleá (...) se dieron la mano, acompañadas de una misma música, de aire ligero en las unas y lento en las otras" (RODRÍGUEZ MARÍN, 1929: 11). Y Machado y Álvarez aludió al tránsito de las "alegrías andaluzas" (los jaleos populares) a las "tristezas gitanas" (léase jaleos agitanados, fueran soleares u otros cantes/bailes). Por su parte Más y Prat (1882: 59) escribió que los bailes teatrales eran de compás ligero, mientras el flamenco era "esclavo de la línea escultórica y del pausado compás". En esta clave podemos mirar el famoso cuadro de John Singer Sargent, El Jaleo ${ }^{16}$.

\section{BAILES DE JALEO JUNTO A BAILES FLAMENCOS}

Durante todo el XIX los bailes de jaleo academizados compartieron espacios con los bailes flamencos, a los que en su primera época podemos retener conceptualmente como jaleos populares agitanados y profesionalizados, ofrecidos en fiestas de pago. Vemos el olé, el vito y las soleares bailados en una misma función en 1892 (ORTIZ NUEVO, 2012: 20). En el Diario El Porvenir (18. III. 1897) leemos que se bailó el jaleo denominado La Cachucha en una fiesta para extranjeros acaudalados (ORTIZ NUEVO, 2012: 23). Y en El Porvenir (26. III. 1897), el "jaleo denominado El Ole" acompañado al piano. A finales del siglo XIX, el Olé y la Cachucha eran designados expresamente como jaleos.

Ortiz Nuevo engloba bailes como El Jaleo de Jerez, La Cachucha, La Flamenca, La Malagueña y el Torero, El Vito, El Ole, El Carnaval Español, El Baile de la Macarena, Los Panaderos, La Macarena en las astas del toro y La

16 Museo Isabella Stewart Gardner, http://www.gardnermuseum.org/collection/artwork/1st_floor/spanish_cloister/el_jaleo 
Flor de la Maravilla ..., bajo la siguiente expresión: "absoluto predominio de lo bolero" por encima de lo flamenco propiamente dicho (ORTIZ NUEVO, 2012: 28). Pensamos que tal valoración puede llevar a confusión, si no diferencia la tradición más ortodoxa del bolero de esta otra de bailes de jaleo, que fue la que especialmente convivió con los bailes flamencos en el siglo XIX.

Más que predominio de lo bolero sobre lo flamenco, lo que se observa es que continuaba la convivencia entre bailes de jaleo teatrales (ya bien academizados) y flamencos (versiones populares de jaleos andaluces que experimentaron en el siglo XIX un particular tipo de reelaboración o agitanamiento). Si las fuentes citadas (y otras muchas) posibilitan considerar los bailes flamencos como versiones gitanas o agitanadas de jaleos populares, también permiten concluir que se perfeccionaron a través de su contacto con estas danzas teatrales que el maestro Otero enseñaba a sus alumnas en la década de 1890, como habían hecho antes Miguel y Manuel de la Barrera, La Campanera, Luis Rico, José Segura y otros maestros desde mediados de siglo.

Cierto que además de las academias y funciones dirigidas por maestros, hubo otros ambientes flamencos. Ortiz Nuevo comenta una fiesta de vecinos reseñada en la prensa sevillana de 1890 , en la que hubo repiqueteo de palillos, cantares y acordes de guitarra y en su parte final coplas improvisadas cantando despechos de amor, tras las que "se escucharon voces destempladas, gritos y una infernal algarabía. Varios juerguistas se lanzaron precipitadamente a la calle" (ORTIZ NUEVO, 2012: 18). Podríamos catalogarlo de baile de candil, más o menos flamenco, y puesto que transcurrió en la calle Castilla de Triana, probablemente con predominio de protagonistas gitanos. Sin duda que encontramos diversos tipos de veneros flamencos, unos más populares y otros más académicos, conviviendo a fin de siglo. Así ha seguido sucediendo hasta hoy día.

Concluimos observando que aunque hay datos que indican que también los jaleos teatrales fueron aflamencándose al socaire del auge del flamenco, otros datos indican que a principios del siglo XX no habían desaparecido subsumidos en la emergente escuela flamenca. En la fiesta que montó el maestro Otero en 1902 para el duque de los Abruzzos (ORTIZ NUEVO, 2012: 32), sólo al final, tras las sevillanas, El Olé, Manchegas, La Madrileña, Boleras de Madrid, Olé de la Curra y unas Soleares de Arcas, se reseña "cante y baile flamenco". En la segunda parte de la fiesta se reseñan la Malagueña y el torero, Jaleo de Jerez, Boleras de la Cachucha, El Vito... y al final un número titulado "cante y baile gitano". ¿No nos recuerda a la convivencia entre jaleos gitanos y otros academizados, tal como 40 años antes habían presenciado Émile Guimet y Charles Davillier? La convivencia e incluso mezcla entre jaleos teatrales y bailes flamencos seguía a principios del siglo XX. Las dos "escuelas" (en realidad nunca del todo separadas) seguían interactuando, y de esa interacción surgió un enriquecimiento técnico de los bailes flamencos más elaborados, del tipo de las soleares y las alegrías, los estilos predominantes por esos años.

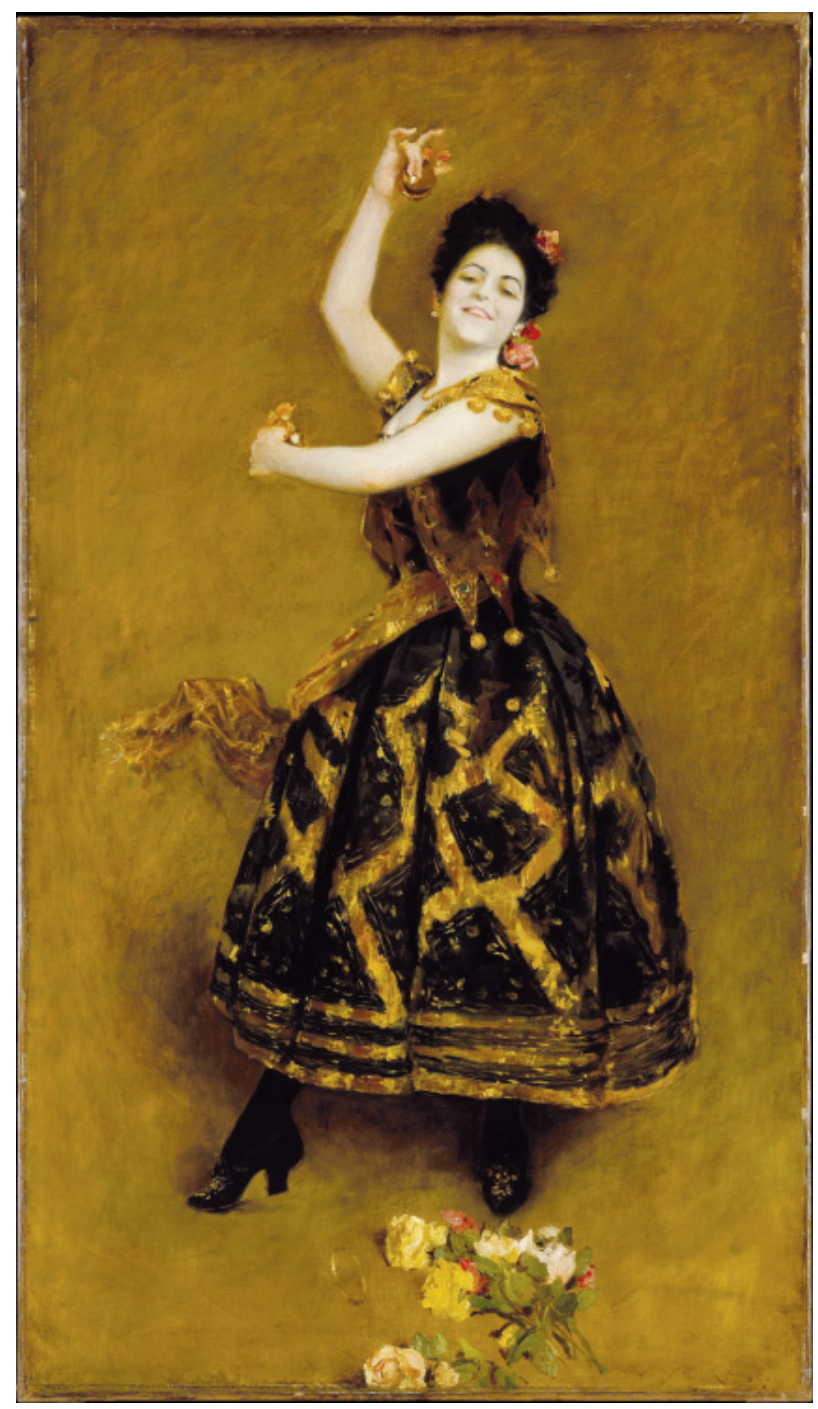

Imagen 07. Carmencita. Óleo sobre lienzo (177.5 x 103.8 $\mathrm{cm})$. William Merritt Chase, 1890.

Fuente: The Metropolitan Museum of New York. http://www.metmuseum.org/art/collection/search/10465. 
Todavía muchas tonadilleras, cupletistas y bailaoras del primer tercio del siglo XX tenían bailes de jaleo en su repertorio. Pero la extraordinaria figura de Antonia Mercé estaba a punto de abrir para la danza española -particularmente a las danzas teatrales- nuevas vías de evolución. Los jaleos iperdieron su dinamismo, o fueron más bien reinventados por la Argentina? Sea lo que fuere, en su larga historia habían contribuido de manera singular al surgimiento de la escuela de baile flamenco.

\section{BIBLIOGRAFÍA}

Alonso, Celsa, La Canción Lírica Española en el siglo XIX. Madrid, Ediciones del ICCMU, 1998.

Arriaga, Gerardo, "La jácara instrumental en la música española barroca". En LOBATO, 2014: 179-194.

Berlanga, Miguel Ángel, Bailes de candil andaluces y fiesta de verdiales. Otra visión de los fandangos. Málaga, Servicio de Publicaciones de la Diputación, 2000.

Berlanga, Miguel Ángel, "The Fandangos of southern Spain in the Context of other Spanish and American Fandangos”. En Música Oral del Sur, n. 12, 2015, pp. 171184. http://www.centrodedocumentacionmusicaldeandalucia.es/export/sites/default/publicaciones/pdfs/02miguel-berlanga.pdf

Blas Vega, José, Los Cafés Cantantes de Sevilla. Madrid, Cinterco, 1987.

Blasis, Carlo, Manuel complet de la Danse. Paris, Libería Enciclopédica de Boret, 1830. Edición consultada: https://books.google.es/books?id=mFa2IF7HtvQC\&p rintsec $=$ frontcover $\&$ hl=es \&source $=$ gbs ge summary $\mathrm{r} \& \mathrm{cad}=0 \# \mathrm{v}=$ onepage $\& \mathrm{q} \& \mathrm{f}=$ false.

Bravo Liñán, Francisco, "Un aspecto de la fisonomía cultural de la ciudad de Cádiz reflejado en la prensa ilustrada: su inclinación teatral", en Cuadernos de Ilustración y Romanticismo, n. 3, 1993, pp. 7-42.

Cairón, Antonio, Compendio de las principales reglas del baile... con una explicación exacta, y modo de ejecutar la mayor parte de los bailes conocidos en España, tanto antiguos como modernos, Madrid, Imprenta de Repullés, 1820. Edición consultada: BNE, Biblioteca Digital Hispánica, M/868 (http://bdh-rd.bne.es/viewer. vm?pid=d-2175469).

Cantos Casenave, Marieta, "José Sanz Pérez y el andalucismo teatral del siglo XIX", en Romero Ferrer, Alberto.Moreno, A. (ed.), Manuel García: de la tonadilla escénica a la ópera española (1775-1832), Cádiz, UCA, 2006. 89-90.
Castro Buendía, Guillermo, "Jaleos y soleares. La diferenciación estilística entre el jaleo y la soleá como origen del estilo flamenco", Sinfonía Virtual, 25, julio 2013. www.sinfoniavirtual.com [Consulta 30.VII.2014].

Castro Buendía, Guillermo, Génesis Musical del Cante Flamenco, Sevilla, Libros con Duende, 2014 (2 vol).

Cavia Naya, Victoria, La Castañuela Española y la Danza. Baile, Música e Identidad, Valencia, Mahali, 2013.

Cotarelo y Mori, Emilio, Catálogo descriptivo de la gran colección de comedias escogidas que consta de cuarenta y ocho volúmenes, impresos de 1652 a 1704. Edición digital a partir de Boletín de la Real Academia Española, XVIII (1931), en Biblioteca Virtual Miguel de Cervantes, http://www.cervantesvirtual.com/obra/ catalogo-descriptivo-de-la-gran-coleccion-de-comedias-escogidas-que-consta-de-cuarenta-y-ocho-volumenes-impresos-de-1652-a-1704/.

D’Aulnoy, Marie Catherine, Relación del viaje de España (1691), Madrid, Akal, 1986.

Esses, Maurice, Dance and Instrumental Diferencias in Spain During the 17th and 18th Centuries. Stuyvessant, NY, Pendragon Press, 1994 (3 vols).

Estébanez Calderón, Serafín, Escenas Andaluzas (1846), Edición original consultada: Madrid, A. Pérez Dubrull, 1883, en Biblioteca Virtual Miguel de Cervantes. http://www.cervantesvirtual.com/obra-visor/ escenas-andaluzas--0/html/ff06d424-82b1-11df-acc7002185ce6064_4.html\#I_5_.

Flórez, María Asunción, Música teatral en el Madrid de los Austrias durante el Siglo de Oro, Madrid, ICCMU, 2006.

Ford, Richard, Las cosas de España, Madrid, Turner, 1988 ( $1^{\text {a }}$ ed: 1844$)$.

Gautier, Théophile, Voyae en Espagne (1840). Consultada $5^{\mathrm{a}}$ edición, París, 1845: http://gallica.bnf.fr/ark:/12148/ bpt6k5685444r .

Gelardo Navarro, José, "Dos bailes, dos identidades. Escuela Bolera. Baile Flamenco", Sinfonía Virtual, 24, 2013. http://www.sinfoniavirtual.com/revista/024/.

Gosálvez Lara, José Carlos, De la Gallarda a la Jácara. Libros de Danza en la Biblioteca Nacional de España (Siglos XVI-XIX), Folleto del Día Internacional de la Danza, Museo de la Biblioteca Nacional, 2011.

Guimet, Émile, A travers l'Espagne. Lettres Familières, Lyon, Charles Mèra, 1862, En: Gallica, Biblioteca Nacional de Francia, http://gallica.bnf.fr/ark:/12148/ bpt6k56775572.r=Guimet.

Gutiérrez de Alba, José María, El pueblo andaluz. Sus tipos, sus costumbres, sus cantares (ca 1870). 
Iza Zamácola, Juan Antonio, Colección de las mejores coplas de Seguidillas, Tiranas y Polos que se han compuesto para cantar a la guitarra, Madrid, Demófilo, $1982\left(1^{\mathrm{a}}\right.$ ed.1788).

Iza Zamácola, Juan Antonio, Elementos de la ciencia contradanzaria para que los currutacos, pirracas y madamitas de nuevo cuño aprendan por principios a bailar las contradanzas por sí solos o con las sillas de su casa, Madrid, Viuda de Joseph García, 1796. En http://www.cervantesvirtual.com/obra/elementos-dela-ciencia-contradanzaria-para-que-los-currutacos-pirracas-y-madamitas-de-nuevo-cuno-puedan-aprenderlas-contradanzas--0/.

Lavaur, Luis, Teoría Romántica del Cante Flamenco, Sevi1la, Signatura, 1999. $1^{a}$ Edición: Madrid, Editora Nacional, 1976.

Lobato, María Luisa / BÈGUE, Alain (ed.s), Literatura y Música del Hampa en los siglos de Oro, Madrid, Visor Libros, 2014.

Machado y Álvarez, Antonio, Colección de Cantes Flamencos (1881), Madrid, Demófilo, 1975.

Marín, Rafael, Aires Andaluces. Método de Guitarra por Música y Cifra, Ediciones de la Posada, Ayuntamiento de Córdoba, 1995, Edición facsímil de la $1^{\text {a }}$ edición (Madrid, 1902).

Martínez de la Peña, Teresa, Teoría y Práctica del Baile Flamenco, Madrid, Aguilar, 1969.

Más y Prat, Benito, "Costumbres andaluzas. Bailes de palillos y flamencos", La Ilustración española y americana, año XXVI, n. 28, Madrid 30. VII. 1882.

Massip y Moyá, Félix, Diccionario analítico de todas las palabras castellanas que pueden tener en la oración diferente significado, Valencia, Imprenta de José María Ayoldi, 1866.

Mera, Guadalupe: "Los ilustrados y la danza a principios del siglo 19. Polémicas sobre la construcción de una identidad nacional frente al modelo francés", en Martínez del Fresno, Beatriz (ed): Coreografiar la historia europea: cuerpo, política, identidad y género en la danza, UNE, Oviedo, 2011, pp. 174195.

Molina, Ricardo /Mairena, Antonio, Mundo y formas del cante flamenco, Granada/Sevilla, Al-Andalus, 1979.

Moreno muñoz, María José, La danza teatral en el siglo XVII, Córdoba, Servicio de Publicaciones de la Universidad, 2008.

Navarro García, José Luis, Historia del Baile Flamenco, vol 1, Sevilla, Signatura Ediciones, 2008 (especialmente pp. 187 y ss).
Navarro Garacía, José Luis / Pablo Lozano, Eulalia, El baile flamenco. Una aproximación histórica, Córdoba, Almuzara, 2005.

Núñez, Faustino, "Cuando lo bolero se hizo flamenco", en http://elafinadordenoticias.blogspot.com.es/2012/07/ cuando-el-bolero-se-hizo-flamenco.html.

Ocón, Eduardo, Cantos españoles, Colección de aires nacionales y populares, $2^{\mathrm{a}}$ ed., Málaga, 1888.

Ortiz Nuevo, José Luis, ¿Se sabe algo? Viaje al conocimiento del arte flamenco según los testimonios de la prensa sevillana del XIX, Sevilla, El Carro de la Nieve, 1990.

Ortiz Nuevo, José Luis, Coraje. Del maestro Otero y su paso por el baile, Sevilla, Libros con Duende, 2012.

Plaza, Rocío, El Flamenco y los Románticos, Sevilla, Ed. Bienal, 1999.

Plaza, Rocío, Egron Lundgren. Un pintor sueco en Sevilla, Sevilla, UNE, 2012.

Reyes, Lénica / Jaramillo, José Miguel, "El baile de la petenera española del XIX desde una perspectiva etnomusicológica", en Murga Castro, Idoia, et al, Líneas actuales de investigación en la danza española, Madrid, Nebrija Fundación, 2012, pp. 225-240: http://www. gerinel.org/ficheros/baile.pdf.

Rodríguez Calderón, Juan Jacinto, La bolerología o Cuadro de las Escuelas del baile bolero, tales cuales eran en 1794 y 1795 en la Corte de España, Ed consultada: Biblioteca Virtual Miguel de Cervantes: http://www.cervantesvirtual.com/obra/la-bolerologia-o-cuadro-de-las-escuelas-del-baile-bolerotales-cuales-eran-en-1794-y-1795-en-la-corte-deespana--0/, de la edición de Philadelphia, Zacharias Poulfon, 1807.

Rodríguez Marín, Francisco, El Alma de Andalucía en sus mejores coplas amorosas, Madrid, Tipografía de Archivos, 1929.

Roldán Fidalgo, Cristina, "Bailes y danzas en los teatros de Madrid”, en Sanjuán, José Ignacio, Estudios Musicales del Clasicismo. Danza y ballet, 2, Madrid y San Cugat, Arpegio, 2015, pp. 51 a 87.

Romero Ferrer, Alberto, "El sainete y la tonadilla escénica en los orígenes del costumbrismo andaluz", en Álvarez Barrientos, J. / Lolo, Begoña (eds.), Teatro y Música en España: los géneros breves en la segunda mitad del siglo XVIII, Madrid, Universidad Autónoma / CSIC, 2008, pp. 237-262.

Ruiz Mayordomo, María José, "Espectáculos de baile y danza. De la Edad Media al siglo XVIII", en Amorós, Andrés / Díez Borque, José Ma $\mathrm{M}^{\mathrm{a}}$ Historia de los espectáculos en España, Madrid, Castalia, 1999, pp. 273-318. 
Salinas, José Luis, "Cincuenta años de baile en la memoria y el sentir del tocaor Félix de Utrera”, La Caña, n. 12, 1995, pp. 63-65.

Udaeta, José de, La castañuela española. Origen y evolución, Ediciones del Serbal, Barcelona, 1987.
Valdivia Sevilla, Francisco, La guitarra rasgueada en España durante el siglo XVII, Málaga, Servicio de Publicaciones de la Universidad, 2015.

Recibido: 12.04.2016

Aceptado: 03.05.2016 